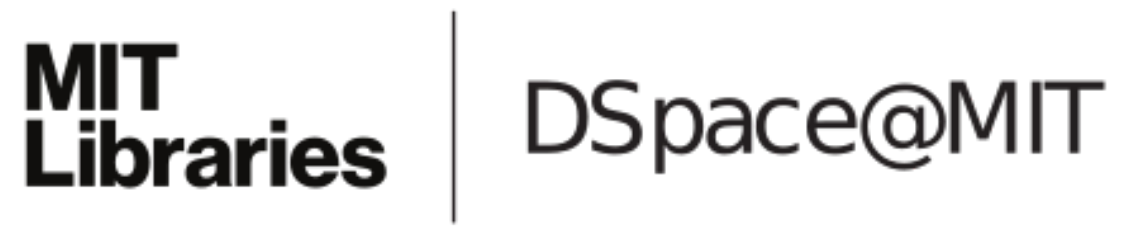

\author{
MIT Open Access Articles
}

\section{Mussismilia braziliensis White Plague Disease Is Characterized by an Affected Coral Immune System and Dysbiosis}

The MIT Faculty has made this article openly available. Please share how this access benefits you. Your story matters.

As Published: https://doi.org/10.1007/s00248-020-01588-5

Publisher: Springer US

Persistent URL: https://hdl.handle.net/1721.1/132065

Version: Author's final manuscript: final author's manuscript post peer review, without publisher's formatting or copy editing

Terms of Use: Article is made available in accordance with the publisher's policy and may be subject to US copyright law. Please refer to the publisher's site for terms of use. 


\section{Mussismilia braziliensis white plague disease is characterized by an affected coral immune system and dysbiosis}

Cite this article as: Silva-Lima, A.W., Froes, A.M., Garcia, G.D., Tonon, L.A.C., Swings J, Cosenza C.A.N., Medina, M., Penn, K., Thompson, J.R., Thompson, C.C., Thompson, F.L., Mussismilia braziliensis white plague disease is characterized by an affected coral immune system and dysbiosis, Microbial Ecology, doi: 10.1007/s00248-020-01588-5

This Author Accepted Manuscript is a PDF file of a an unedited peer-reviewed manuscript that has been accepted for publication but has not been copyedited or corrected. The official version of record that is published in the journal is kept up to date and so may therefore differ from this version.

Terms of use and reuse: academic research for non-commercial purposes, see here for full terms. http://www.springer.com/gb/open-access/authors-rights/aam-

terms-v1 


\section{Mussismilia braziliensis white plague disease is characterized by an affected coral immune system and dysbiosis}

Silva-Lima, A.W. ${ }^{1}{ }^{*}$, Froes, A.M. ${ }^{1}$, Garcia, G.D. ${ }^{1,2}$, Tonon, L.A.C. ${ }^{1,2}$, Swings $\mathrm{J}^{1,2}$, Cosenza C.A.N. ${ }^{2}$, Medina, M. ${ }^{3}$, Penn, K. ${ }^{4}$, Thompson, J.R. ${ }^{4}$, Thompson, C.C. ${ }^{1,2}$, Thompson, F.L. ${ }^{1,2 *}$

${ }^{1}$ Laboratório de Microbiologia, Instituto de Biologia, Universidade Federal do Rio de Janeiro (UFRJ), Av. Carlos Chagas Fo. S/N - CCS - IB - Lab de Microbiologia - BLOCO A (Anexo) A3 - sl 102, Cidade Universitária, Rio de Janeiro, RJ, Brasil 21941-599

${ }^{2}$ Sage/Coppe, Centro de Gestão Tecnológica-CT2, Rua Moniz de Aragão, no.360 - Bloco 2, Ilha do Fundão - Cidade Universitária, Rio de Janeiro, Brasil 21.941-972 . e-mail: fabianothompson1@gmail.com

${ }^{3}$ Pennsylvania State University, 324 Mueller Lab, University Park, PA 16802, USA

${ }^{4}$ Department of Civil and Environmental Engineering, Massachusetts Institute of Technology, Cambridge, MA, USA

\section{ABSTRACT}

Infectious diseases are one of the major drivers of coral reef decline worldwide. White plague-like disease (WPL) is a widespread disease with a complex etiology that infects 
several coral species, including the Brazilian endemic species Mussismilia braziliensis. Gene expression profiles of healthy and WPL-affected M. braziliensis were analyzed in Winter and Summer seasons. The de novo assembly of the M. braziliensis transcriptome from healthy and white plague samples produced a reference transcriptome containing 119,088 transcripts. WPL-diseased samples were characterized by repression of immune system and cellular defense processes. Autophagy and cellular adhesion transcripts were also repressed in WPL samples, suggesting exhaustion of the coral host defenses. Seasonal variation leads to plasticity in transcription with up-regulation of intracellular signal transduction, apoptosis regulation and oocyte development in the Summer. Analysis of the active bacterial rRNA indicated that Pantoea bacteria were more abundant in WPL corals, while Tistlia, Fulvivirga and Gammaproteobacteria Ga0077536 were more abundant in healthy samples. Cyanobacteria proliferation was also observed in WPL, mostly in the winter. These results indicate a scenario of dysbiosis in WPLaffected M. braziliensis, with the loss of potentially symbiotic bacteria and proliferation of opportunistic microbes after the start of the infection process.

Keywords: Coral Reefs; Mussismilia braziliensis, White Plague; Metatranscriptomic analysis; Dysbiosis.

\section{INTRODUCTION}

A worldwide decline in reef-building coral cover has been observed in recent decades due to a combination of local and global changes [1]. Coral infectious diseases have also intensified, triggered by, for example, local pollution and/or elevated sea temperature $[2,3]$. The prevalence of coral diseases is expected to increase further in future scenarios of global climate change $[4,5,6]$. White plague (WPL) disease is the most prevalent coral disease in the Atlantic and is known to infect more than 40 coral species $[4,5,7]$. WPL is characterized by a thin line of coral tissue loss, resulting in exposed skeletons adjacent to healthy tissue, with varying disease progression rates [4].

Culture-independent approaches have revealed a diverse microbial consortium in coral colonies with WPL, indicating a complex etiology of this disease $[8,9,10,11,12]$. 
Bacteria, eukaryotes and viruses may be involved in tissue loss diseases in different coral species $[13,14,15,16,17]$, but the best-known etiologic agents of tissue loss disease belong to Proteobacteria. Vibrio coralliilyticus causes white syndrome in Indo-Pacific corals [18]; Aurantimonas coralicida is the etiological agent of tissue loss disease in Dichocoenia stokesi in the Caribbean [19]; and Thalassomonas loyana has been proposed to cause tissue loss disease in Favia favus in the Red Sea [20].

WPL is widespread in the Abrolhos, the main reef bank in the Southwestern Atlantic Ocean (SAO), affecting the endemic reef-building coral Mussismilia braziliensis [5, 21, 22]. The etiology of WPL in Abrolhos is not completely understood, and previous studies indicated a dysbiosis scenario, with the proliferation of opportunistic infections and different potential etiologic agents $[21,22,23,24,25]$. Dysbiosis and the consequently impaired microbiome, might cause negative impacts on the coral host, impoverishing the host health condition and making it more vulnerable to infections [26, 27]. In these conditions, identification of WPL etiological agents is elusive, demanding careful manipulative experiments [28,29]. WPL-affected M. braziliensis are enriched with Vibrio, Alteromonadales, Bacteroidetes and sulfate-reducing bacteria [21, 22, 23, 24, 25]. qPCR analysis showed an increased activity of total Vibrio spp. and Vibrio coralliilyticus in WPL-affected M. braziliensis [30]. It is not clear if these microbes represent primary infectious agents or are simply opportunistic or saprophitic, taking advantage of necrotic coral tissue as a nutrition source. Despite the high prevalence of WPL diseases, M. braziliensis physiological and cellular responses to WPL are not known.

Pathogen infections cause modulation of the coral host immune system, including induction of the innate immune system, associated cellular signaling pathways and mobile phagocytic cells, the amoebocytes [31,32,33]. Humoral response includes the induction of cellular responses such as phagocytosis, apoptosis, and autophagy and activation of lysosome enzymes [31,32,34,35]. Melanization, production of reactive oxygen species and phenoloxidase proteolytic activity provide a physicochemical barrier to infections $[31,32,33,35,36]$. Coral mucus, gastroderm, and other tissues harbor diverse symbiotic bacterial and viral communities, which can provide both physical and biological barriers to infections $[32,37]$. These barriers might function as an earlier 
mechanism to prevent disease infection in corals, as suggested by the lack of correlation between immune responses and survival after Vibrio spp. infections in O. faveolata [12].

WPL incidence is higher on summer, as a possible effect of microbial proliferation induced by higher temperatures [05]. However, seasonal variation might also affect the cnidarian immune system, as high temperatures and coral bleaching modulate coral immune pathways $[32,38]$. Recent studies shown that the establishment and maintenance of cnidarian-Symbiodiniaceae symbiosis leads to modulation of the hosts immune system, with the induced expression of TGF-B and repression of nitric oxide production and the NF-kappaB signaling pathway [39,40]. In this sense, coral mucus and the cnidarian immune system are also responsible for the recognition and control of the diverse symbiotic interactions in the coral holobiont, making them important not only for ecological maintenance [41,42], but also for the evolution of coral lineages [43].

Despite some advances in understanding host-microbe interactions in health and disease transitions, little is known about holobiont gene expression during WPL in the SAO endemic Mussismilia corals. Our aim was to obtain the metatranscriptomic profiles of both healthy and diseased M. braziliensis corals. This is the first attempt to shed light on the holobiont metatranscriptome to identify possible cellular processes in the coral host and associated changes in microbial communities in WPL-affected M. braziliensis.

\section{MATERIALS AND METHODS}

\section{Sampling}

Coral fragments (approx. $5 \mathrm{~cm}^{2}$ ) were collected from shallow waters reefs (4-10 meters deep) at two different locations in Abrolhos Marine National Park (Brazil, SISBIO permit 27147-2): (a) Archipelago (17 ${ }^{\circ} 96^{\prime} 43^{\prime \prime} \mathrm{S} / 38^{\circ} 70^{\prime} 06^{\prime \prime} \mathrm{W}$ ) and (b) Parcel dos Abrolhos $\left(17^{\circ} 57^{\prime} 32.7^{\prime \prime} \mathrm{S} / 38^{\circ} 30^{\prime} 20.3^{\prime \prime} \mathrm{W}\right)$. Tissue fragments of asymptomatic M. braziliensis (hereafter Healthy, $\mathrm{n}=5$ ) and $M$. braziliensis visually affected with white-plague-like disease ( $W P L, \mathrm{n}=9$ ) were collected during scuba diving with a hammer and a chisel [24]. Samples were collected in the austral winter (August/2011:two Healthy; four WPL) and summer (Feb/2012: three Healthy; five WPL). Mean seawater surface temperature (SST) was $25.0^{\circ} \mathrm{C}$ in $\mathrm{Aug} / 2011$ and $27.2^{\circ} \mathrm{C}$ in $\mathrm{Feb} / 2012$, slightly above the maximum monthly 
mean temperature for the Abrolhos reefs $\left(26.9{ }^{\circ} \mathrm{C}\right.$, Figure S1). Although higher SST probably occurred in shallow reefs, mass bleaching was not reported for the Abrolhos in this period. In both seasons, diseased samples presented the same morphology, with no visual signs of bleaching, and samples were collected at the tissue necrosis band. Diseased and healthy samples were collected in separate short dives. Coral fragments were collected on polypropylene tubes underwater, and transferred to RNAlater filled tubes and stored in liquid nitrogen upon returning to the boat.

\section{RNA extraction}

Each individual tissue fragment (100 $\mathrm{mg}$ ) was grounded in liquid nitrogen using a mortar and pestle. Total RNA was extracted using a modified TRIzol (Invitrogen ${ }^{\mathrm{TM}}$, Carlsbad, CA, USA) and chloroform protocol [44]. TRIzol reagent (Invitrogen ${ }^{\mathrm{TM}}$, Carlsbad, CA, USA) was added to the samples and mixed by vortexing for $2 \mathrm{~s}$. The tubes were kept at room temperature for $5 \mathrm{~min}$, after which $200 \mu \mathrm{L}$ of chloroform was added, and the solution was mixed for $15 \mathrm{~s}$ by hand shaking. The tubes were incubated at room temperature for $3 \mathrm{~min}$ and centrifuged at $2000 \mathrm{rpm}$ for $15 \mathrm{~min}$. RNA purification was performed with the RNeasy mini kit (Qiagen, Valencia, CA, USA) according to the manufacturer's instructions. RNA integrity was checked in a $1 \%$ agarose gel, and the RNA concentration quality and purity were verified in a NanoDrop ND-1000 spectrophotometer (NanoDrop Technologies, Wilmington, DE, USA). RNA was stored at $-80^{\circ} \mathrm{C}$ until processing.

RNA was treated with DNAse $(50 \mu 1$ RNA in DEPC water to $50 \mu 1$ 10x DNAse buffer and $2 \mu \mathrm{l}$ DNAse I were incubated at $37^{\circ} \mathrm{C}$ for $1 \mathrm{~h} .1 \mu 1$ of $0.5 \mathrm{M}$ EDTA was added and heated at $75{ }^{\circ} \mathrm{C}$ for $10 \mathrm{~min}$ to inactivate). Precipitation was performed as follow ( 0.1 volume of $5 \mathrm{M} \mathrm{NH}_{4} \mathrm{OA}_{\mathrm{c}}+5 \mu \mathrm{g}$ glycogen +3 volume $100 \%$ ethanol were added and kept at $-20{ }^{\circ} \mathrm{C}$ overnight. RNA was centrifuged at $12.000 \mathrm{~g}$ for $30 \mathrm{~min}$ at $4{ }^{\circ} \mathrm{C}$. The supernatant was discarded and $1 \mathrm{~mL}$ ice cold $70 \%$ ethanol was added and mixed by vortex. A new Centrifugation was performed at $12.000 \mathrm{~g}$ for $10 \mathrm{~min}$ at $4{ }^{\circ} \mathrm{C}$. The supernatant was carefully discarded and RNA was res-suspended in $30 \mu \mathrm{l}$ DEPC water. The purification for large-scale transcription reactions was performed by using the MEGAclear ${ }^{\mathrm{TM}}$ 
Transcription Clean-Up Kit (Ambion) according to the manufacturer's instructions. At the end, RNA was resuspended in $30 \mu 1$ of TE buffer. Depletion of potential mammal RNA contamination (rRNA and mRNA from human, mouse or rat origin) was performed by RNA hybridization with MICROBEnrich ${ }^{\mathrm{TM}}$ Kit (Ambion), according to the manufacturer's instructions. Depletion of bacterial rRNA (16S and 23S) was performed by MICROBExpress ${ }^{\mathrm{TM}}$ Kit (Ambion) and mRNA-ONLY ${ }^{\mathrm{TM}}$ Prokaryotic mRNA isolation Kit (Ecogen), according to the manufacturer's instructions.

cDNA library preparation and sequencing

Synthesis of cDNA was performed with the SeqPlex RNA amplification KIT (Sigma Aldrich) with the following amplification program: $18^{\circ} \mathrm{C}$ for $10 \mathrm{~min}, 25^{\circ} \mathrm{C}$ for $10 \mathrm{~min}, 37{ }^{\circ} \mathrm{C}$ for $30 \mathrm{~min}, 42{ }^{\circ} \mathrm{C}$ for $10 \mathrm{~min}, 70{ }^{\circ} \mathrm{C}$ for $20 \mathrm{~min}$ and a $4{ }^{\circ} \mathrm{C}$ hold. cDNA samples were sheared in a bioruptor according to the instructions of the Quick Blunting Kit (New England Biolabs). A clean-up step with a PCR cleanup kit was performed, and the samples were eluted in a volume of $32 \mu \mathrm{l}$. An A' overhang was added by using the Klenow fragment (3'-5' exonuclease negative) according to the NEB\#M0212 protocol, and sample-specific adapters were ligated using a ligation kit (NEB\# M2200). After running the samples on an agarose gel electrophoresis (2\%),prepared with TAE, cDNA bands at the range of 350-500 bp were excised. The extracted cDNA was enriched via qPCR, monitoring the cDNA copy numbers, and the obtained cDNA was cleaned and eluted in $30 \mu 1$ of Buffer EB. Finally, the library size distribution was checked using a 2100 Bioanalyzer system (Agilent Inc., Waltham, MA) and a High Sensitivity DNA Kit (Agilent Inc., Waltham, MA). cDNA libraries were quantified in a 7500 Real-Time PCR system (Applied Biosystems) using KAPA Library Quantification Kit (Kapa Biosystems). PhiX sequencing control v3 (Illumina Inc., San Diego, CA, USA) was added at $1 \%$, and paired-end sequencing $(2 \times 250 \mathrm{bp})$ was performed on the MiSeq platform (Illumina Inc., San Diego, CA, USA) at Parsons Lab, Massachusetts Institute of Technology.

Data preprocessing and de novo assembly 
Paired-end cDNA fastq sequences from coral were demultiplexed into separate files for each sample by barcodes using the script FASTQ/A Barcode Splitter from FASTX-toolkit version 0.0.14 [45], with a maximum barcode mismatch score of 2 . Adapters were removed from both the 3 and 5' ends using cutadapt [46]. Quality control was performed with prinseq lite version 0.20 .4 [47] by trimming poly-A/T tails of more than $5 \mathrm{bp}$, filtering reads with an average quality of less than $30(\mathrm{Q}>30)$, removing duplicates and ambiguous bases, and filtering reads by length ranging from 30 to $230 \mathrm{bp}$. Sequence quality was checked with FastQC version 0.11 .3 [48] before and after quality control. High-quality overlapping paired-end reads were collapsed to form a longer sequence using pear [49].

Ribosomal RNA depletion is often incomplete [50], and remaining ribosomal sequences were filtered out, mapping the high-quality reads to small (16S/18S SSU) and large (23S/28S LSU) rRNA sequences, retrieved from the SILVA database project, release 119 [51]. Read mapping was performed with version 2.2 .3 using the -very-sensitive-local parameter [52].

After quality control and rRNA removal, two healthy (MBH2, MBH5) and one diseased sample (WP8) presented a low number of reads $(<150,000)$ and were not used for the transcriptomic analysis. Collapsed and uncollapsed paired reads from the

remaining eleven samples were pooled in a cross-assembly with Trinity version 2.0.6 [53] for de novo assembly using the --single end option. Assembly was performed with all reads across all samples combined as the input. The assembled transcriptome and the associated sequenced RNA libraries were deposited in the NCBI transcriptome repository under BioProject accession no PRJNA543846.

\section{Transcriptomic analysis}

The assembled transcripts were annotated via Blastx comparisons with the NCBI$\mathrm{nr}$ and the Uniprot (TrEMBL and SwissProt) databases (downloaded in June 2015), with an e-value of 10e-5. Gene ontology annotations were determined by mapping Uniprot IDs to the UniProt-GOA database [54]. 
High-quality mRNA reads were mapped back to the assembled transcriptome (bowtie2), and RSEM [55] was used to estimate sample-specific transcript abundance. Transcripts with low read support ( $<15$ reads) were filtered out, and mRNA libraries were normalized to account for library size and composition (TMM) [56]. A classic MDS was constructed with the 500 transcripts with the largest mean leading pairwise fold-changes, evaluating the effect of disease category (healthy or WPL diseased) and sampling season (winter or summer) among samples [56]. Enrichment of gene ontology (GO) terms was evaluated using GO_MWU, a rank-based analysis measuring whether transcripts in a GO term are consistently up or down-regulated [57]. GO_MWU was conducted with signed $\log (\mathrm{p}$-values) with a false-discovery rate of 0.1 .

Additionally, traditional GO enrichment analysis was conducted on the set of differentially expressed transcripts. Differentially expressed (DE) transcripts associated with the two categories (disease and season) were evaluated with $e d g e R$ glm likelihood ratio test, called at a 0.05 significance level and adjusted to a 0.05 false-discovery rate (Benjamini-Hochberg correction, [56]). Enriched GO categories were checked with Fisher's exact test at a 0.05 significance level with the 'weight01' algorithm to account for the GO topology, using the Bioconductor package topGO [58].

Symbiodiniaceae, bacterial and viral community structure

Symbiodiniaceae community composition in M. braziliensis samples was assessed by Blastn mapping of high-quality RNA reads to a local Symbiodiniaceae ITS2 database, comprised by the dereplicated database described in [59], combined with the Symbiodiniaceae sequences previously observed in M. braziliensis [60]. Symbiodiniaceae ITS2 sequences were retrieved with a minimum alignment length of 150 bp and 95\% identity, allowing the presence of partial ITS2 matches. A t-test was used to compare differences in the relative abundance of total Symbiodiniaceae reads between disease conditions, and between sampling seasons. A logistic regression was used to assess the effect of hosting Symbiodinium A4 (the non-dominant symbiont) on disease outcome with the package $g \operatorname{lm}$ in R [61].

Bacterial genera potentially indicative of disease conditions or sampling season, were 
assessed with the remaining ribosomal RNA in the sequenced cDNA libraries. In contrast to high-throughput 16s metabarcoding sequencing, this analysis focused on finding bacterial biomarkers on the most abundant representatives of the active bacterial community [62]. Ribosomal RNA reads were aligned (blastn) to the SILVA SSU (16S/18S) database, release 132 [51]. rRNA reads with at least 95\% identity over $200 \mathrm{bp}$ were retrieved for abundance analysis, and sequences with either mitochondrial or chloroplast origin were removed from the analysis. Relative abundances of each bacterial genus were used to evaluate whether a microorganism is consistently associated with one of the conditions, based on LEfSe analysis [63]. A heatmap was constructed with the 30 most abundant bacterial genera, based on the average of the geometric mean among Healthy and WPL samples. Relative abundances were power-transformed and bacterial genera were clustered based on Pearson correlation among samples.

The assembled transcriptome was used to assess the composition of the viral community associated with $M$. braziliensis, through tBlastx searches against the NCBI viral genomic RefSeq database (November/2016), with an e-value threshold of 10e-15. For each transcript, tBlastx best hit was retrieved for taxonomic analysis, and sequences were assigned to viral families by parsing the NCBI taxonomic tree with a custom shell script. The distribution of viral families was quantified in the total transcriptome $(\mathrm{n}=119,088)$ and in the sets of exclusively healthy (transcripts supported by reads in healthy libraries and no read support in any diseased samples, $n=12,788$ ) or WPL transcripts (transcripts supported by diseased with no read support in healthy samples, $\mathrm{n}=28,395)$. Similarly, the distribution of viral families was quantified in the winter $(n=14,630)$ and summer transcripts $(n=17,876)$. The occurrence of over- or underrepresented viral families in each condition was evaluated by a hypergeometric test at the 0.05 significance level after Bonferroni correction of false positives [64].

\section{RESULTS}

Sequencing of all 14 samples resulted in a total of 10,406,652 paired-end reads. A total of 8,004,107 paired-end reads were retained (average length of $270 \mathrm{bp}$ ) after quality control. After the removal of ribosomal RNA, a total of 6,415,051 reads were retained (Table S1). The de novo assembly of the M. braziliensis transcriptome from healthy and 
white plague samples produced a reference transcriptome with a N50 of $527 \mathrm{bp}$, containing 119,088 transcripts. A total of 38,040 transcripts (32.9\%) were annotated against the UniProt protein database (Table S2).

\section{Differential expression and Gene Ontology enrichment analysis}

Transcript expression analysis indicate an effect of both the disease categories and sampling season on the similarity between samples (Figure 1). Rank-based GO_MWU analysis indicated that WPL samples were characterized by the down-regulation of immune response, cellular defense response, autophagy and DNA/RNA metabolic processes (Figure 2). Photosynthetic dark reactions, carbohydrate and peptide biosynthetic processes were up-regulated in samples from diseased corals (Figure 2). Coral samples obtained in the summer were downregulated in DNA integration, and upregulated in positive regulation of gene expression and carbohydrate biosynthetic process.

A total of 212 and 251 transcripts were differentially expressed (DE) on disease and season, respectively (Tables S3 and S4). Only two transcripts were differentially expressed in both disease and season: an unannotated transcript downregulated in WPL and summer samples; and a transcript coding for "Eukaryotic initiation factor 4A-I", downregulated in WPL and upregulated in summer samples. DE transcripts in the disease were associated to biosynthetic processes, protein transport and methylation, and macroautophagy and endosome functioning (Table S5). Most of the DE transcripts in the disease were down-regulated transcripts (202 of 212). DE transcripts in the season contrast were associated to regulation of gene expression, intracellular signal transduction (including multiple signaling pathways as Toll, TNF, JNK, NF-kappaB), regulation of apoptosis, and oocyte development (Tables1, S5, S6). In total, 177 transcripts were upregulated in the summer.

Symbiodiniaceae, bacterial and viral community structure

Mussismilia braziliensis preferentially hosts Symbiodiniaceae ITS2 types C3/C1 and 
A4 (Figure 3), and most of the retrieved ITS2 (437 of 514) reads aligned to sequences previously observed in Mussismillia spp corals [58]. Our results indicate that Cladocopium $\mathrm{C} 3 / \mathrm{C} 1$ is the primary symbiont of $M$. braziliensis, but the relative abundance of Symbiodinium A4 can reach up to 50\%. There were no differences in the relative abundance of total Symbiodiniaceae ITS2 reads, either between disease conditions $(\mathrm{t}=-1.12, p$-value $=0.294)$ or sampling seasons $(\mathrm{t}=-0.46$; $\mathrm{p}$-value $=0.655)$. Also, there was no association between the relative abundance of Symbiodinium A4 and disease outcome $(p=0.274)$.

Blastn analysis identified 13,955 bacterial rRNA reads, after the exclusion of mitochondrial and chloroplast rRNA. As inferred from the abundance of bacterial rRNA reads, the most abundant groups in the active $M$. braziliensis bacterial community were Vibrio, Leptospira, Candidatus Amoebophilus, Trichodesmium and an unclassified Gammaproteobacteria GA0077536 (Figure 4). LEfSe analysis indicated that the bacterial genus Pantoea (Gammaproteobacteria: Erwiniaceae) was associated with WPL samples, while Tistlia (Alphaproteobacteria: Rhodospirillaceae), Fulvivirga (Bacteroidia: Flammeovirgaceae) and Gammaproteobacteria Ga0077536 were associated with healthy colonies (Figure 3). Considering the season contrast, Stenotrophonomas (Gammaproteobacteria: Xanthomonadaceae), and the cyanobacteria Lyngbia and Schizotrix were more abundant on winter samples, while Francisella (Gammaproteobacteria: Francisellaceae) was more abundant on summer samples.

A total of 1,646 viral transcripts were identified via tBlastx analysis. Overall, the viral transcripts were dominated by Phycodnaviridae (21.9\%) and Mimiviridae (14.1\%), viral families associated with Symbiodiniaceae (Figure 5). The bacteriophage families Myoviridae and Siphoviridae were also represented, as were families associated with metazoan hosts including Polydnaviridae, Poxviridae, Iridoviridae, Baculoviridae and Herpesviridae (Figure 5). A total of 114 and 262 viral transcripts were observed in the Healthy and WPL corals, respectively. Myoviridae $(p=0.0005)$ and Siphoviridae $(p=0.0003)$ were enriched in WPL, while Herpesviridae was enriched in healthy transcripts $(p=0.0002)$. Considering the season contrast, 109 and 165 transcripts were observed in the winter and summer samples, respectively. Myoviridae was enriched in winter samples $(p=0.0003)$. 


\section{DISCUSSION}

The metatranscriptomic analysis indicate that disease condition and seasonal environmental variation have diverging effects on the M. braziliensis meta-transcriptomic response. Results of WPL-affected samples suggest a widespread down-regulation of transcription, with the exhaustion of the cnidarian immune system and cellular defense responses (Figure 2, Table 1). Contrastingly, seasonal environmental variation leads to a coordinated regulation, indicating plasticity in the $M$. braziliensis transcriptional response (Figure 2, Table 1). Moreover, the etiology of WPL in M. braziliensis involves proliferation of opportunistic microbes and loss of potentially symbiotic bacteria.

M. braziliensis processes associated with WPL: Immune system, cellular defense response and autophagy

The results of this study indicate a vulnerable M. braziliensis, evidenced by the repression of immune system, cellular defense response and autophagy in WPL samples (Figure 2, Tables 1, S3, S5). Selective autophagy is the main route for degradation of invading pathogens in eukaryotic cells, and its inhibition in WPL samples is supported by the repression of macroautophagy, the autophagy regulator Beclin 1, of E3-ubiquitin ligase and endosome/lisosome transcripts (FIVE, Huntigtin, mvb2, snx4; Figure 2, Tables 1, S3) $[65,66]$. Inhibition of autophagy was also observed in disease-susceptible $O$. faveolata, but not in the resistant Porites astreoides, when exposed to bacterial lipopolysaccharides (LPS) [35]. Induction of cell adhesion and phagocytosis transcription were observed in the Eunicea sp. octocoral with black band disease [35].

Lower activity of vesicle transport in WPL M. braziliensis is evidenced by the repression of transcripts related to cytoskeleton and intracellular motor activity (Dynein, Tubulin-B, unconventional myosins 1a and 5a, WASH2C, Table S3) [67]. Impacts on the cellular cytoskeleton and tissue organization is also indicated by the repression of transcripts involved in cell migration, tissue development and the maintenance of extracellular matrix (GO: Basolateral plasma membrane, Table S5; ADGRE3, EPHA4, 
FMCA1, F-Actin, mucin, pcd1, Table S3) [68,69]. More specifically, reduced calcification is indicated by the inhibition of carbonic anydrase, an extracellular calcium pump (FMCAI) and transcripts associated with the organic matrix of the aragonitic skeleton (mucin, pcd1) [70,71]. Repression of cellular adhesion transcripts was also observed in WPL-affected $O$. faveolata [14]. These processes may be related to necrosis of the coral tissue. Necrosis can also be caused by bacterial enzymatic processes. Metalloproteases from the coral pathogen Vibrio coralliilyticus are known to cause tissue necrosis in Pocillopora damicornis and other Pacific corals $[18,72,73]$. In this model, pathogen infection induces a temperature dependent innate immune response and cytokine production in $P$. damicornis $[73,74]$.

Upregulated in WPL samples, photosynthesis, carbohydrate and organonitrogen biosynthesis processes are putatively associated with Symbiodiniaceae (Figure 2). The repression of TGF-B and nitric oxide signaling (NOS) regulator nostrin suggests a breakdown of the symbiosis, with a possible transition to free-living lifestyle in Symbiodiniaceae (Table S3) [39]. Deleted in malignant brain tumors 1 (dmbt1), a pattern recognition protein associated with symbiosis maintenance [12] was also repressed in WPL (Table S3). To a lesser extent, carbon fixation and photosynthesis transcripts were also upregulated in summer samples (Figure 2, Table S4).

Seasonal effects on M. braziliensis metatranscriptomic response

Positive regulation of gene expression in summer samples was associated with upregulation of signal transduction pathways and protein phosphorylation, suggesting a coordinated meta-transcriptomic response to environmental variation in M. braziliensis. This response shows a remarkable similarity with the proposed cnidarian environmental stress response (ESR) [75], with the up-regulation of general stress response transcripts (dnaJ and $h s p 1$ ), the apoptotic regulator Bcl-2 and $T N F$ factors (Tables S4, S6). These results support the hypothesis that seasonal variation selects for plasticity of ESR in $M$. braziliensis transcription. Seasonal plasticity was also observed on Porites astreoides [76], while a constitutive uploading of the ESR genes was observed in Acropora hyacinthus subjected to acute daily environmental variation [75]. 
It is striking to note that immune system and stress-related biological processes were affected differently in the disease and season contrasts. Regulation of apoptosis was repressed in WPL samples, while the apoptotic regulator Bcl-2 and TNF factors were induced in the summer (Figure 2, Tables S4, S5). Similarly, cell adhesion and migration were repressed in WPL, but induced in summer samples (Figure 2, Table S3). Given the mild summer conditions in 2012 and the positive regulation of gene expression, these results suggest that the observed seasonal biological processes reflect $M$. braziliensis physiological response. Interestingly, M. braziliensis spawning period begins in the summer [77], when induction of oocyte development transcripts was observed (Tables S4, S6).

\section{Dysbiosis and changes in microbial communities in WPL colonies}

Bacterial genera that are often associated with corals were among the most abundant in healthy M. braziliensis samples, including Candidatus Amoebophilus, Vibrio spp, Flavobacteriaceae NS5 Marine group (Figure 4) [78,79,80]. Changes in the $M$. braziliensis microbiome composition were associated with the affected host immune system, with the proliferation of opportunistic species and the loss of nondominant potentially symbiotic species, suggesting a condition of dysbiosis [26, 27]. The biomarker genera of the Healthy condition (Tistlia, Fulvivirga and the Gammaproteobacteria Ga0077536) formed a cluster with bacteria commonly observed in healthy corals, as Blatocatella and Candidatus Amoebophilus [Figure 3, 78]. Although some of the species associated with healthy M. braziliensis might indeed be commensal bacteria [26], it is noteworthy that the single described species in Tistlia (T. consotensis) is a nitrogen-fixing bacterium [80]. Efficient nitrogen regulation is essential to the coral-Symbiodiniaceae interaction, and changes in this cycle are often observed in dysbiosis conditions, either caused by disease or environmental factors [10,11, 82].

Pantoea, identified as a WPL biomarker, is a diverse genus that includes commensal species and pathogens of plants and animals [83]. Pantoea was previously associated with WPD in Diploria strigosa, but not in Siderastrea siderea [84]. In the present study, Pantoea clustered together with cyanobacteria which proliferated in some WPL samples, 
but not consistently. Proliferation of opportunistic cyanobacteria is possibly related to the colonization of the exposed skeleton in diseased colonies [5]. Cyanobacteria proliferation was more evident in the winter, when Lyngbia and Schizotrix were more abundant and the relative abundance of Trichodesmiun reached 65\% in the sample WP01 (Figure 4). Changes in bacterial community composition were accompanied by enrichment of the phage families Myoviridae and Siphoviridae in WPL samples. The observed enrichment of the phage families Myoviridae in WPL-affected and winter samples (Figure 5) was largely driven by cyanobacterial phages (Table S7). Virus-bacteria interaction in coral samples may have diverse roles, ranging from viral-facilitated infections to viruses conferring protection to bacterial and coral hosts from invading pathogens $[37,85]$.

Sampling and sequencing strategy

In this study, a cross-sectional comparison of healthy and diseased M. braziliensis was presented. However, it is known that the effect of diseases on coral immune system varies with time $[32,33,42]$. Coral immune system and signaling pathways can be induced by pathogen infection, but decline with disease progression [42]. Physical injuries also elicit immune responses, that decline over time with healing [33]. WPL-affected $O$. faveolata showed repression of cellular adhesion transcripts, but increased transcription of the ubiquitin degradation pathway [14]. It remains to be investigated whether the observed discrepancies between WPL affected $M$. braziliensis and $O$. faveolata indicate different stages of the same etiology or different etiologies for WPL disease in each coral species.

Healthy and WPL M. braziliensis coral colonies were collected both in winter and summer, but the limited number of samples obtained after processing precluded a full factorial analysis of the interaction between disease and season categories. The pooling of different samples in each category (e.g. winter and summer samples in the WPL samples) tend to inflate biological variation between replicates, leading to a lower statistical power to differentiate between conditions $[56,86]$. Statistical power of the study was also affected by the relatively low sequencing depth. A sequencing platform with higher throughput would improve transcript assembly and quantification in the meta- 
transcriptome, leading to a more precise holobiont response [86]. In this sense, it is expected that the obtained DE transcripts are dominated by the most abundant transcripts, but it is unlikely that the observed biological responses are caused by the pooling of samples. This conclusion is supported by the small overlap on DE transcripts, biological processes and biomarkers between the disease and season categories.

\section{CONCLUSION}

This study brings new insight into the metatranscriptomic response of Mussismilia corals. The exhaustion of the coral defenses on WPL disease andthe lower responsiveness of the coral host to infections are evidenced by the repression of immune processes, autophagy and cellular adhesion transcripts. Dysbiosis and proliferation of opportunists follows the onset of WPL disease. Despite the potentially synergistic effect of higher temperatures and disease infection, a different transcriptomic response was observed in the season categories, with the active regulation of ESR genes.

The macroscopic observations of tissue necrosis can be attributed to the inhibition of transcripts associated with cellular adhesion and the proliferation of potentially tissue necrotizing bacteria. The collection of induced and repressed genes identified in WPL as well as the detection of potentially symbiotic microorganisms in healthy coral colonies in the present study may serve as tools for monitoring coral health in face of escalating global changes and infectious diseases.

\section{ACKNOWLEDGMENTS}

The authors thank CNPq, CAPES, and FAPERJ for financial support.

\section{REFERENCES}

[1] Hughes TP et al. (2003). Climate change, human impacts, and the resilience of coral reefs. Science. 301, 929-933.

[2] Loya, Y., 2004. The coral reefs of Eilat-past, present and future: three decades of coral community structure studies. In Coral health and disease (pp. 1-34). Springer, Berlin, 


\section{AUTHOR ACCEPTED MANUSCRIPT}

Heidelberg.

[3] Carpenter KE, Abrar M, Aeby G, et al. (2008). One-third of reef-building corals face elevated extinction risk from climate change and local impacts. Science. 321:560-563.

[4] Weil E (2004) Coral reef diseases in the wider Caribbean. Rosenberg E, Loya Y, eds. Coral health and disease. Heidelberg: Springer. pp 35-68.

[5] Francini-Filho, R.B., Moura, R.L., Thompson, F.L., Reis, R.M., Kaufman, L., Kikuchi, R.K. and Leão, Z.M., 2008. Diseases leading to accelerated decline of reef corals in the largest South Atlantic reef complex (Abrolhos Bank, eastern Brazil). Marine Pollution Bulletin, 56(5), pp.1008-1014.

[6] Zvuloni, A., Artzy-Randrup, Y., Katriel, G., Loya, Y. and Stone, L., 2015. Modeling the impact of white-plague coral disease in climate change scenarios. PLoS computational biology, 11(6), p.e1004151.

[7] Precht, W.F., Gintert, B.E., Robbart, M.L., Fura, R. and Van Woesik, R., 2016. Unprecedented disease-related coral mortality in Southeastern Florida. Scientific Reports, 6, p.31374.

[8] Pantos, O., Cooney, R.P., Le Tissier, M.D., Barer, M.R., O'donnell, A.G. and Bythell, J.C., 2003. The bacterial ecology of a plague-like disease affecting the Caribbean coral Montastrea annularis. Environmental microbiology, 5(5), pp.370-382.

[9] Sunagawa, S., DeSantis, T.Z., Piceno, Y.M., Brodie, E.L., DeSalvo, M.K., Voolstra, C.R., Weil, E., Andersen, G.L. and Medina, M., 2009. Bacterial diversity and White Plague Disease-associated community changes in the Caribbean coral Montastraea faveolata. The ISME journal, 3(5), p.512.

[10] Roder, C., Arif, C., Daniels, C., Weil, E. and Voolstra, C.R., 2014. Bacterial profiling of White P lague Disease across corals and oceans indicates a conserved and distinct disease microbiome. Molecular ecology, 23(4), pp.965-974.

[11] Roder, C., Arif, C., Bayer, T., Aranda, M., Daniels, C., Shibl, A., Chavanich, S. and Voolstra, C.R., 2014. Bacterial profiling of White Plague Disease in a comparative coral species framework. The ISME journal, 8(1), p.31. 
[12] Wright RM, et al, (2017). Intraspecific differences in molecular stress responses and coral pathobiome contribute to mortality under bacterial challenge in Acropora millepora. Scientific reports, 7(1), p.2609.

[13] Soffer N, Brandt ME, Correa AM, Smith TB, Thurber RV. (2014). Potential role of viruses in white plague coral disease. ISME J. 8(2):271-83.

[14] Daniels CA, Baumgarten S, Yum LK, Michell CT, Bayer T, Arif C, Roder C, Weil E and Voolstra CR (2015) Metatranscriptome analysis of the reef-building coral Orbicella faveolata indicates holobiont response to coral disease. Front. Mar. Sci. 2:62. doi: 10.3389/fmars.2015.00062

[15] Correa, A., Ainsworth, T.D., Rosales, S.M., Thurber, A.R., Butler, C.R. and Vega Thurber, R.L., 2016. Viral outbreak in corals associated with an in situ bleaching event: atypical herpes-like viruses and a new megavirus infecting Symbiodinium. Frontiers in microbiology, 7, p.127.

[16] Work TM, Russell R, Aeby GS. Tissue loss (white syndrome) in the coral Montipora capitata is a dynamic disease with multiple host responses and potential causes. Proceedings of the Royal Society B: Biological Sciences. 2012 Sep 5;279(1746):4334-41. [17] Meyer JL, Paul VJ, Teplitski M. Community shifts in the surface microbiomes of the coral Porites astreoides with unusual lesions. PLoS One. 2014 Jun 17;9(6):e100316.

[18] Sussman, M., Willis, B.L., Victor, S. and Bourne, D.G., 2008. Coral pathogens identified for white syndrome (WS) epizootics in the Indo-Pacific. PLoS one, 3(6), p.e2393.

[19] Richardson LL, Goldberg WM, Kuta KG et al. (1998). Florida's mystery coral killer identified. Nature. 392:557-558.

[20] Thompson, F.L., Barash, Y., Sawabe, T., Sharon, G., Swings, J. and Rosenberg, E., 2006. Thalassomonas loyana sp. nov., a causative agent of the white plague-like disease of corals on the Eilat coral reef. International journal of systematic and evolutionary microbiology, 56(2), pp.365-368.

[21] Garcia, G.D., Gregoracci, G.B., Santos, E.D.O., Meirelles, P.M., Silva, G.G., Edwards, R., Sawabe, T., Gotoh, K., Nakamura, S., Iida, T. and de Moura, R.L., 2013. 
Metagenomic analysis of healthy and white plague-affected Mussismilia braziliensis corals. Microbial ecology, 65(4), pp.1076-1086.

[22] Garcia, G.D., Santos, E.D.O., Sousa, G.V., Zingali, R.B., Thompson, C.C. and Thompson, F.L., 2016. Metaproteomics reveals metabolic transitions between healthy and diseased stony coral Mussismilia braziliensis. Molecular ecology, 25(18), pp.4632-4644.

[23] Reis, A.M.M., Araújo Jr, S.D., Moura, R.L., Francini-Filho, R.B., Pappas Jr, G., Coelho, A.M.A., Krüger, R.H. and Thompson, F.L., 2009. Bacterial diversity associated with the Brazilian endemic reef coral Mussismilia braziliensis. Journal of applied microbiology, 106(4), pp.1378-1387.

[24] De Castro, A.P., Araújo, S.D., Reis, A.M., Moura, R.L., Francini-Filho, R.B., Pappas, G., Rodrigues, T.B., Thompson, F.L. and Krüger, R.H., 2010. Bacterial community associated with healthy and diseased reef coral Mussismilia hispida from eastern Brazil. Microbial ecology, 59(4), pp.658-667.

[25] Fernando, S.C., Wang, J., Sparling, K., Garcia, G.D., Francini-Filho, R.B., de Moura, R.L., Paranhos, R., Thompson, F.L. and Thompson, J.R., 2015. Microbiota of the major South Atlantic reef building coral Mussismilia. Microbial ecology, 69(2), pp.267280.

[26] Pita, L., Rix, L., Slaby, B.M., Franke, A. and Hentschel, U., 2018. The sponge holobiont in a changing ocean: from microbes to ecosystems. Microbiome, 6(1), p.46.

[27] Zaneveld JR, McMinds R, Thurber RV. Stress and stability: applying the Anna Karenina principle to animal microbiomes. Nature microbiology. 2017 Sep;2(9):17121.

[28] Pollock FJ, Morris PJ, Willis BL, Bourne DG. The urgent need for robust coral disease diagnostics. PLoS pathogens. 2011 Oct 20;7(10):e1002183.

[29] Sweet, M.J. and Bulling, M.T., 2017. On the importance of the microbiome and pathobiome in coral health and disease. Frontiers in Marine Science, 4, p.9.

[30] Chimetto Tonon, L.A., Thompson, J.R., Moreira, A.P., Garcia, G.D., Penn, K., Lim, R., Berlinck, R.G., Thompson, C.C. and Thompson, F.L., 2017. Quantitative detection of active vibrios associated with white plague disease in Mussismilia braziliensis corals. Frontiers in microbiology, 8, p.2272. 
[31] Sutherland KP, Porter JW, Torres C (2004) Disease and immunity in Caribbean and Indo-Pacific zooxanthellate corals. Mar Ecol Prog Ser 266:273-302.

[32] Mydlarz, L.D., McGinty, E.S. and Harvell, C.D., 2010. What are the physiological and immunological responses of coral to climate warming and disease? Journal of Experimental Biology, 213(6), pp.934-945.

[33] van de Water, J.A., Ainsworth, T.D., Leggat, W., Bourne, D.G., Willis, B.L. and van Oppen, M.J., 2015. The coral immune response facilitates protection against microbes during tissue regeneration. Molecular ecology, 24(13), pp.3390-3404.

[34] Reed, K.C., Muller, E.M. and van Woesik, R., 2010. Coral immunology and resistance to disease. Diseases of aquatic organisms, 90(2), pp.85-92.

[35] Fuess, L.E., Pinzón C, J.H., Weil, E., Grinshpon, R.D. and Mydlarz, L.D., 2017. Life or death: disease-tolerant coral species activate autophagy following immune challenge. Proceedings of the Royal Society B: Biological Sciences, 284(1856), p.20170771.

[36] Libro, S., Kaluziak, S.T. and Vollmer, S.V., 2013. RNA-seq profiles of immune related genes in the staghorn coral Acropora cervicornis infected with white band disease. PloS one, 8(11), p.e81821.

[37] Barr, J.J., Auro, R., Furlan, M., Whiteson, K.L., Erb, M.L., Pogliano, J., Stotland, A., Wolkowicz, R., Cutting, A.S., Doran, K.S. and Salamon, P., 2013. Bacteriophage adhering to mucus provide a non-host-derived immunity. Proceedings of the National Academy of Sciences, 110(26), pp.10771-10776.

[38] Pinzón JH, Kamel B, Burge CA, Harvell CD, Medina M, Weil E, Mydlarz LD. Whole transcriptome analysis reveals changes in expression of immune-related genes during and after bleaching in a reef-building coral. Royal Society open science. 2015 Apr 1;2(4):140214.

[39] Detournay O, Schnitzler CE, Poole A, Weis VM (2012) Regulation of cnidariandinoflagellate mutualisms: evidence that activation of a host TGF $\beta$ innate immune pathway promotes tolerance of the symbiont. Developmental \& Comparative Immunology, 38(4), 525-537.

[40] Mansfield KM et al (2017). Transcription factor NF-אB is modulated by symbiotic 
status in a sea anemone model of cnidarian bleaching. Scientific reports, 7(1), 1-14.

[41] Davy, S.K., Allemand, D. and Weis, V.M., 2012. Cell biology of cnidariandinoflagellate symbiosis. Microbiol. Mol. Biol. Rev., 76(2), pp.229-261.

[42] Palmer, C.V., 2018. Immunity and the coral crisis. Communications biology, 1(1), p.91.

[43] Cunning, R., Bay, R.A., Gillette, P., Baker, A.C. and Traylor-Knowles, N., 2018. Comparative analysis of the Pocillopora damicornis genome highlights role of immune system in coral evolution. Scientific reports, 8(1), p.16134.

[44] Chomczynski, P. and Mackey, K., 1995. Short technical reports. Modification of the TRI reagent procedure for isolation of RNA from polysaccharide-and proteoglycan-rich sources. Biotechniques, 19(6), pp.942-945.

[45] Pearson, W.R., Wood, T., Zhang, Z. and Miller, W., 1997. Comparison of DNA sequences with protein sequences. Genomics, 46(1), pp.24-36.

[46] Martin, M., 2011. Cutadapt removes adapter sequences from high-throughput sequencing reads. EMBnet. journal, 17(1), pp.10-12.

[47] Schmieder, R. and Edwards, R., 2011. Quality control and preprocessing of metagenomic datasets. Bioinformatics, 27(6), pp.863-864.

[48] Andrews, S., 2010. FastQC: a quality control tool for high throughput sequence data.

[49] Zhang J, Kobert K, Flouri T, Stamatakis A. (2014). PEAR: a fast and accurate Illumina Paired-End reAd mergeR. Bioinformatics. 30(5): 614-620.

[50] Petrova OE, Garcia-Alcalde F, Zampaloni C, Sauer K. Comparative evaluation of rRNA depletion procedures for the improved analysis of bacterial biofilm and mixed pathogen culture transcriptomes. Scientific reports. 2017 Jan 24;7:41114.

[51] Quast, C., Pruesse, E., Yilmaz, P., Gerken, J., Schweer, T., Yarza, P., Peplies, J. and Glöckner, F.O., 2012. The SILVA ribosomal RNA gene database project: improved data processing and web-based tools. Nucleic acids research, 41(D1), pp.D590-D596.

[52] Langmead, B. and Salzberg, S.L., 2012. Fast gapped-read alignment with Bowtie 2. Nature methods, 9(4), p.357. 


\section{AUTHOR ACCEPTED MANUSCRIPT}

[53] Haas BJ, Papanicolaou A, Yassour M, Grabherr M, Blood PD, Bowden J, et al. (2013). De novo transcript sequence reconstruction from RNA-Seq: reference generation and analysis with Trinity. Nat Protoc. 8(8):10.1038/nprot.2013.084. Available online at: http://transdecoder.github.io

[54] Camon, E., Magrane, M., Barrell, D., Lee, V., Dimmer, E., Maslen, J., Binns, D., Harte, N., Lopez, R. and Apweiler, R., 2004. The gene ontology annotation (goa) database: sharing knowledge in uniprot with gene ontology. Nucleic acids research, 32(suppl_1), pp.D262-D266.

[55] Li, B. and Dewey, C.N., 2011. RSEM: accurate transcript quantification from RNASeq data with or without a reference genome. BMC bioinformatics, 12(1), p.323.

[56] Robinson, M.D., McCarthy, D.J. and Smyth, G.K., 2010. edgeR: a Bioconductor package for differential expression analysis of digital gene expression data. Bioinformatics, 26(1), pp.139-140.

[57] Wright, R. M., Aglyamova, G. V., Meyer, E., and Matz, M. V. (2015). Gene expression associated with white syndromes in a reef building coral, Acropora hyacinthus. BMC Genomics 16:371. doi: 10.1186/s12864-015-1540-2

[58] Alexa, A. and Rahnenfuhrer, J., 2010. topGO: enrichment analysis for gene ontology. R package version, 2(0), p.2010.

[59] Chen B, Yu K, et al (2019). Latitudinal variation in the molecular diversity and community composition of Symbiodiniaceae in coral from the South China Sea. Frontiers in Microbiology, 10, 1278.

[60] Silva-Lima, A.W., Walter, J.M., Garcia, G.D., Ramires, N., Ank, G., Meirelles, P.M., Nobrega, A.F., Siva-Neto, I.D., Moura, R.L., Salomon, P.S. and Thompson, C.C., 2015. Multiple Symbiodinium Strains Are Hosted by the Brazilian Endemic Corals Mussismilia spp. Microbial ecology, 70(2), pp.301-310.

[61] R Core Team (2018) R: A language and environment for statistical computing. R Foundation for Statistical Computing, Vienna, Austria. URL https:/www.R-project.org/.

[62] Xie, C., Goi, C.L.W., Huson, D.H. et al. RiboTagger: fast and unbiased 16S/18S profiling using whole community shotgun metagenomic or metatranscriptome surveys. 
BMC Bioinformatics 17, 508 (2016) doi:10.1186/s12859-016-1378-x

[63] Segata, N., Izard, J., Waldron, L., Gevers, D., Miropolsky, L., Garrett, W.S. and Huttenhower, C., 2011. Metagenomic biomarker discovery and explanation. Genome biology, 12(6), p.R60.

[64] Rivals, I., Personnaz, L., Taing, L. and Potier, M.C., 2006. Enrichment or depletion of a GO category within a class of genes: which test?. Bioinformatics, 23(4), pp.401-407.

[65] Shibutani, S. T., Saitoh, T., Nowag, H., Münz, C., \& Yoshimori, T. (2015). Autophagy and autophagy-related proteins in the immune system. Nature immunology, 16(10), 1014-1024.

[66] Leprince, C., Le Scolan, E., Meunier, B., Fraisier, V., Brandon, N., De Gunzburg, J. and Camonis, J., 2003. Sorting nexin 4 and amphiphysin 2, a new partnership between endocytosis and intracellular trafficking. Journal of cell science, 116(10), pp.1937-1948.

[67] Woolner S, Bement WM (2009) Unconventional myosins acting unconventionally. Trends in cell biology, 19(6), 245-252.

[68] Yang, C., Pring, M., Wear, M.A., Huang, M., Cooper, J.A., Svitkina, T.M. and Zigmond, S.H., 2005. Mammalian CARMIL inhibits actin filament capping by capping protein. Developmental cell, 9(2), pp.209-221.

[69] Kullander, K. and Klein, R., 2002. Mechanisms and functions of Eph and ephrin signalling. Nature reviews Molecular cell biology, 3(7), p.475.

[70] Moya A, et al (2008). Carbonic anhydrase in the scleractinian coral Stylophora pistillata characterization, localization, and role in biomineralization. Journal of Biological Chemistry, 283(37), 25475-25484.

[71] Ramos-Silva, P., Kaandorp, J., Huisman, L., Marie, B., Zanella-Cléon, I., Guichard, N., Miller, D.J. and Marin, F., 2013. The skeletal proteome of the coral Acropora millepora: the evolution of calcification by co-option and domain shuffling. Molecular biology and evolution, 30(9), pp.2099-2112.

[72] Ben-Haim Y, Thompson FL, Thompson CC, Cnockaert MC, Hoste B, Swings J, Rosenberg E. Vibrio coralliilyticus sp. nov., a temperature-dependent pathogen of the 
coral Pocillopora damicornis. International journal of systematic and evolutionary microbiology. 2003 Jan 1;53(1):309-15.

[73] Zhou Z, Zhao S, Tang J, Liu Z, Wu Y, Wang Y, Lin S. Altered immune landscape and disrupted coral-Symbiodinium symbiosis in the scleractinian coral Pocillopora damicornis by Vibrio coralliilyticus challenge. Frontiers in physiology. 2019 Apr 2;10:366.

[74] Vidal-Dupiol J, Ladrière O, Meistertzheim AL, Fouré L, Adjeroud M, Mitta G. Physiological responses of the scleractinian coral Pocillopora damicornis to bacterial stress from Vibrio coralliilyticus. Journal of Experimental Biology. 2011 May 1;214(9):1533-45.

[75] Barshis DJ et al (2013) Genomic basis for coral resilience to climate change. Proceedings of the National Academy of Sciences, 110(4), 1387-1392.

[76] Kenkel C, Matz M (2016) Gene expression plasticity as a mechanism of coral adaptation to a variable environment. Nature Ecology \& Evolution, 1(1), 1-6.

[77] Pires DO, Castro CB, Ratto CC (1999) Reef coral reproduction in the Abrolhos Reef Complex, Brazil: the endemic genus Mussismilia. Marine Biology, 135(3), 463-471.

[78] Ziegler, M., Seneca, F.O., Yum, L.K., Palumbi, S.R. and Voolstra, C.R., 2017. Bacterial community dynamics are linked to patterns of coral heat tolerance. Nature Communications, 8, p.14213.

[79] Epstein, H.E., Torda, G. and van Oppen, M.J., 2019. Relative stability of the Pocillopora acuta microbiome throughout a thermal stress event. Coral Reefs, 38(2), pp.373-386.

[80] Huggett, M.J. and Apprill, A., 2018. Coral microbiome database: Integration of sequences reveals high diversity and relatedness of coral-associated microbes. Environmental microbiology reports.

[81] Díaz-Cárdenas C, Patel BK, Baena S. Tistlia consotensis gen. nov., sp. nov., an aerobic, chemoheterotrophic, free-living, nitrogen-fixing alphaproteobacterium, isolated from a Colombian saline spring. International journal of systematic and evolutionary microbiology. 2010 Jun 1;60(6):1437-43. 


\section{AUTHOR ACCEPTED MANUSCRIPT}

[82] Rädecker N, Pogoreutz C, Voolstra CR, Wiedenmann J, Wild C. Nitrogen cycling in corals: the key to understanding holobiont functioning?. Trends in microbiology. 2015 Aug 1;23(8):490-7.

[83] Delétoile A, et al (2009) Phylogeny and identification of Pantoea species and typing of Pantoea agglomerans strains by multilocus gene sequencing. Journal of clinical microbiology, 47(2), 300-310.

[84] Cárdenas A, Rodriguez-r LM, Pizarro V, Cadavid LF, Arévalo-Ferro C (2012) Shifts in bacterial communities of two Caribbean reef-building coral species affected by white plague disease. The ISME journal, 6(3), 502-512.

[85] Thurber RV, Payet JP, Thurber AR, Correa AM. (2017). Virus-host interactions and their roles in coral reef health and disease. Nat Rev Microbiol. 15(4):205-216.

[86] Schurch NJ, Schofield P, Gierliński M, Cole C, Sherstnev A, Singh V, Wrobel N, Gharbi K, Simpson GG, Owen-Hughes T, Blaxter M. How many biological replicates are needed in an RNA-seq experiment and which differential expression tool should you use?. Rna. 2016 Jun 1;22(6):839-51.

\section{LEGENDS - TABLES AND FIGURES}

Table 1. Most abundant enriched Biological Process GO terms observed in either the Disease or Season contrasts. Total - number of transcripts observed in the total $M$. braziliensis metatranscriptome, DE transcripts - number of differentially expressed transcripts in either Disease or Season contrasts, Up - Number of induced transcripts in WPL (or Summer) samples, Down - Number of repressed transcripts in WPL (or Summer) samples, p-value - Fisher's exact test.

Figure 1. MDS ordination of the samples, based on the mean $\log 2$-fold change of the 500 most diverging transcripts.

Figure 2. GO enrichment test based ranks of the signed p-value of differential expression among all transcripts (GO_MWU). For the Disease contrast, repressed (red) and induced 


\section{AUTHOR ACCEPTED MANUSCRIPT}

(blue) GO terms in WPL samples (A). For the Season contrast, repressed (red) and induced (blue) GO terms in Summer samples (B). p-values according to the common key for each GO term.

Figure 3. Relative abundance of Symbiodiniaceae ITS2 reads among samples. Underline separate the contrasts (Disease and Season) in sample legend: H - Healthy, WP - WPL samples; W - Winter, S - Summer.

Figure 4. Heatmap of relative abundance of the 30 most abundant bacterial genera among samples. Bacterial genera are clustered based on correlations among samples. Colored boxes indicate genus associated with WPL (red) or healthy (blue) samples, according to LefSe analysis. Underline separate the contrasts (Disease and Season) in sample legend: H - Healthy, WP - WPL samples; W - Winter, S - Summer.

Figure 5. Proportion of transcripts associated with viral families in the total $M$. braziliensis meta-transcriptome (gray), and in each group of the contrasts (Disease: healthy/WPL; Season: Winter/Summer). Asterisks denotes viral families enriched in each group, after Bonferroni correction.

Table S1. Summary of RNA sequencing and quality control results. Samples classified by Disease status and sampling Season. Sequenced PE reads: Total paired-end sequenced reads; PE reads passing $Q C$ : reads passing quality control; Merged reads: number of PE reads merged with PEAR; Unmerged reads: number of unmerged reads (PEAR); read length (bp): average read length (bp) of the combined merged and unmerged cDNA libraries; Percentage of $m R N A$ : percentage of sequences that not match the SILVA database (mRNA reads).

Table S2. Summary statistics for the Mussismilia braziliensis transcriptome assembly.

Table S3. Differentially expressed transcripts in the Disease contrast. Negative values of log-fold change indicates transcripts inhibited in WPL samples, while positive values 
indicate induced transcripts in WPL samples. P-value: adjusted p-value (BH-corrected) of edgeR likelihood ratio test, SwissProt.ID: accession number of the best blastx hit to the SwissProt database; TrEMBL.ID: accession number of the best blastx hit to the TrEMBL database; NCBI.acc: accession number of the best blastx hit to the NCBI-nr database; Gene description according to the SwissProt database (NCBI description in case of no SwissProt hits). GO_BP, GO_MF, GO_CC: assigned GO terms by the Uniprot-KB database.

Table S4. Differentially expressed transcripts in the Season contrast. Negative values of log-fold change indicates transcripts inhibited in Summer samples, while positive values indicate induced transcripts in Summer. P-value: adjusted p-value (BH-corrected) of edgeR likelihood ratio test, SwissProt.ID: accession number of the best blastx hit to the SwissProt database; TrEMBL.ID: accession number of the best blastx hit to the TrEMBL database; NCBI.acc: accession number of the best blastx hit to the NCBI-nr database; Gene description according to the SwissProt database (NCBI description in case of no SwissProt hits). GO_BP, GO_MF, GO_CC: assigned GO terms by the Uniprot-KB database.

Table S5. Complete GO enrichment analysis of differentially expressed transcripts in the Disease contrast. Total - number of transcripts observed in the total M. braziliensis metatranscriptome, DE transcripts: observed number of differentially expressed transcripts in the Disease contrast, Expected: expected number of differentially expressed transcripts in the contrast, p-value: Fisher's exact test.

Table S6. Complete GO enrichment analysis of differentially expressed transcripts in the Season contrast. Total - number of transcripts observed in the total M. braziliensis metatranscriptome, DE transcripts: observed number of differentially expressed transcripts in the Season contrast, Expected: expected number of differentially expressed transcripts in the contrast, p-value: Fisher's exact test.

Table S7. Myoviridae transcripts classified according to support in each each level of the 
comparisons contrasts. Taxonomy annotation based on tblastx analysis with the NCBI Viral RefSeq database.

Figure S1. Seawater surface temperature from Jan/2011 to Dec/2012 for the Abrolhos Reefs (-17.225; -39.000). Mean SST on Feb/2012 was slightly above the max monthly mean, but below the bleaching SST threshold $\left(27.9^{\circ} \mathrm{C}\right)$. "Bleaching Warning" was not elicited in this season. Data from NOAA Coral Reef Watch. 2020, updated daily. NOAA Coral Reef Watch Version 3.0 Daily Global 5-km Satellite Virtual Station Time Series Data for Abrolhos Reefs, Jan. 1, 2011-Dec. 31, 2012. College Park, Maryland, USA: NOAA Coral Reef Watch. Data set accessed 2020-07-06 at https://coralreefwatch.noaa.gov/vs/data.php. 


\section{AUTHOR ACCEPTED MANUSCRIPT}

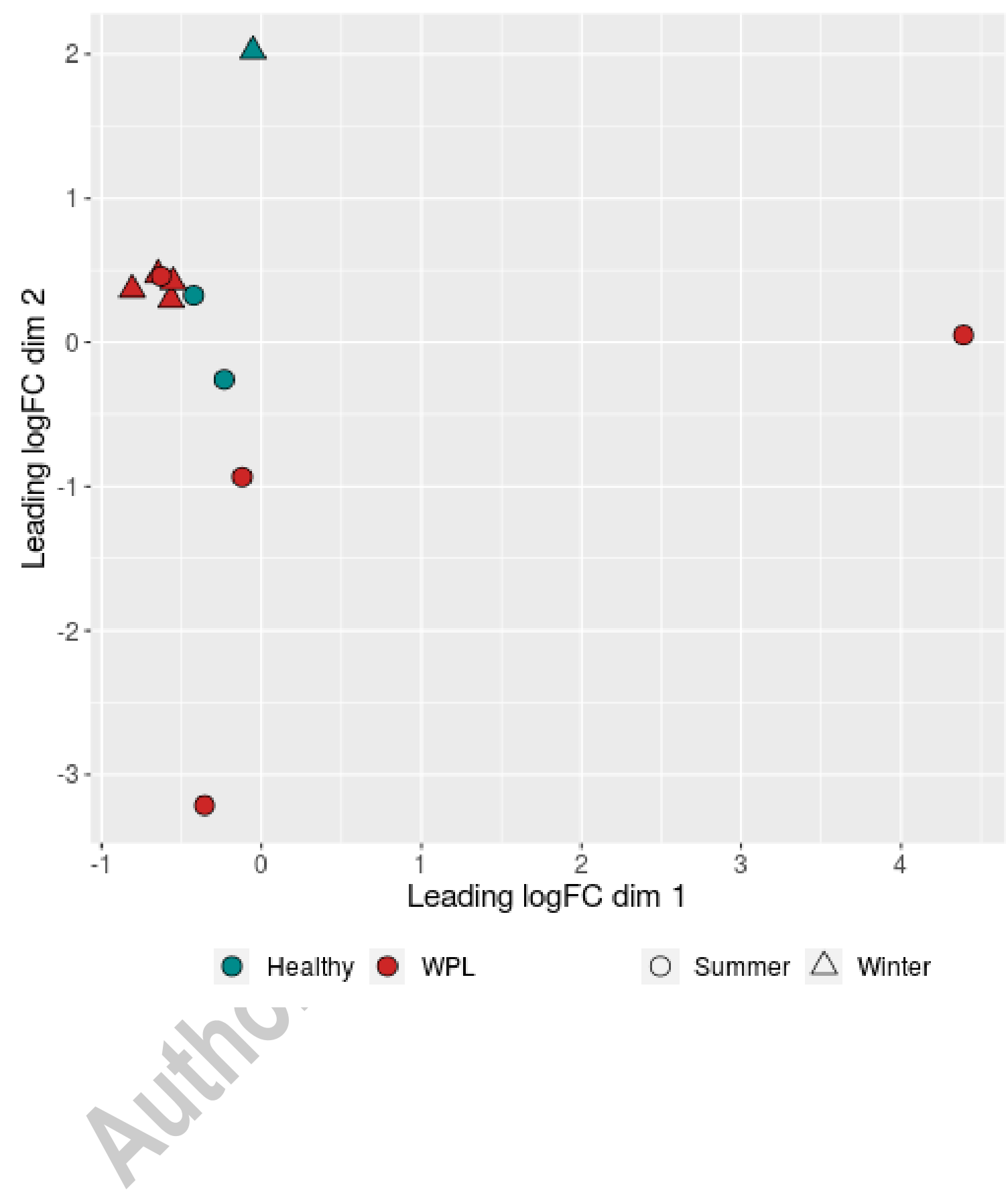

(C) 2020 Springer Science+Business Media, LLC, part of Springer Nature 
A

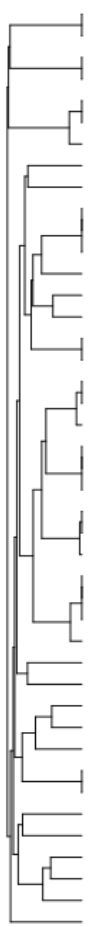

0/46 photosynthesis, dark reaction

$6 / 100$ carbohydrate biosynthetic process

4/98 electron transport chain

20/295 oxidation-reduction process

26/326 cellular amide metabolic process

44/464 organonitrogen compound biosynthetic process

$6 / 55$ regulation of signal transduction by $p 53$ class mediator

69/1164 intracellular transport

4/31 positive regulation of response to DNA damage stimulus

24/331 regulation of cellular response to stress

$3 / 63$ requlation of intrinsic apoptotic signaling pathway

$4 / 58$ negative regulation of cellular protein localization

81/1047 negative regulation of nitrogen compound metabolic process

$3 / 10$ positive regulation of oxidoreductase

3/39 regulation of oxidoreductase

4/35 positive regulation of response to biotic stimulus

$5 / 73$ regulation of response to biotic stimulus

$44 / 526$ regulation of immune system process

$5 / 86$ immune response-regulating cell surface receptor signaling pathway

$37 / 408$ positive regulation of immune system process

$68 / 644$ immune system process

$20 / 182$ cell activation involved in immune response

$2 / 8$ membrane disruption in other organism

14/387 defense response

4/155 defense response to other organism

$31 / 335$ response to biotic stimulus

$3 / 7$ cellular copper ion homeostasis

15/143 response to acid chemical

3/38 regulation of DNA recombination

$30 / 390$ chromatin organization

52/572 DNA metabolic process

14/214 RNA biosynthetic process

$4 / 9$ negative regulation of fatty acid metabolic process

$9 / 123$ response to endoplasmic reticulum stress

$32 / 506$ protein modification by small protein coniugation or removal

$25 / 421$ proteolysis involved in cellular protein catabolic process

$3 / 43$ regulation of mitophagy

\section{$\mathbf{p}<\mathbf{0 . 0 1}$}

$p<0.1$

B

- 5/8 oocyte axis specification

L 116/1194 positive regulation of gene expression

10/46 reductive pentose-phosphate cycle

18/100 carbohydrate biosynthetic process

25/179 DNA integration

4/8 membrane disruption in other organism 


\section{AUTHOR ACCEPTED MANUSCRIPT}

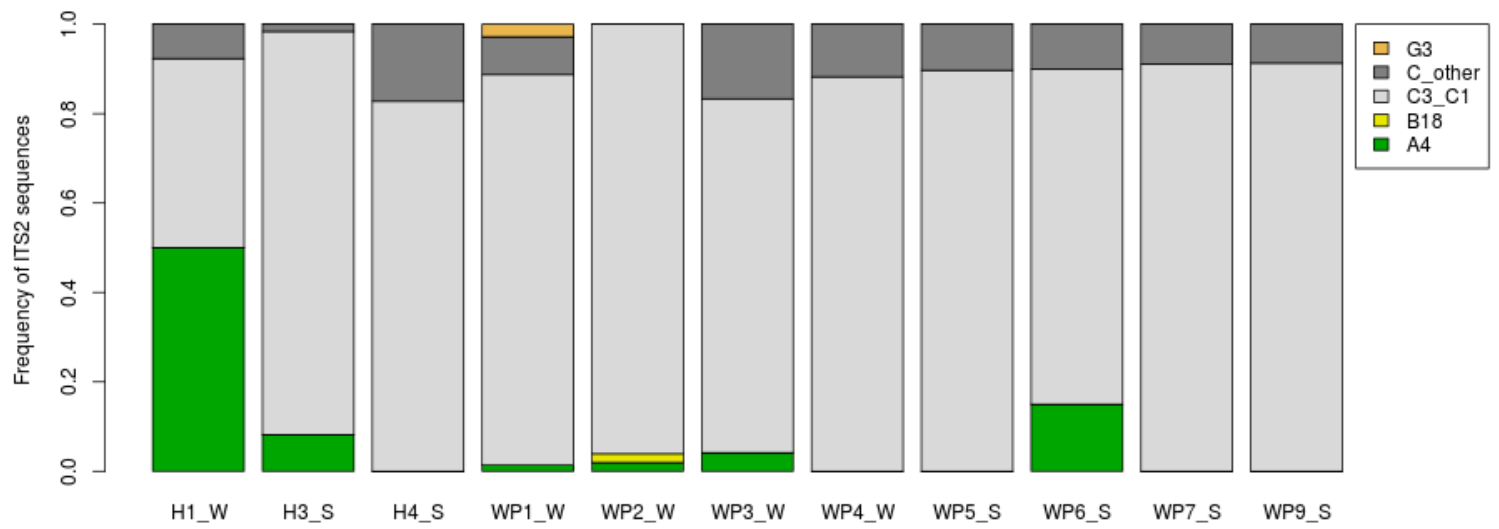




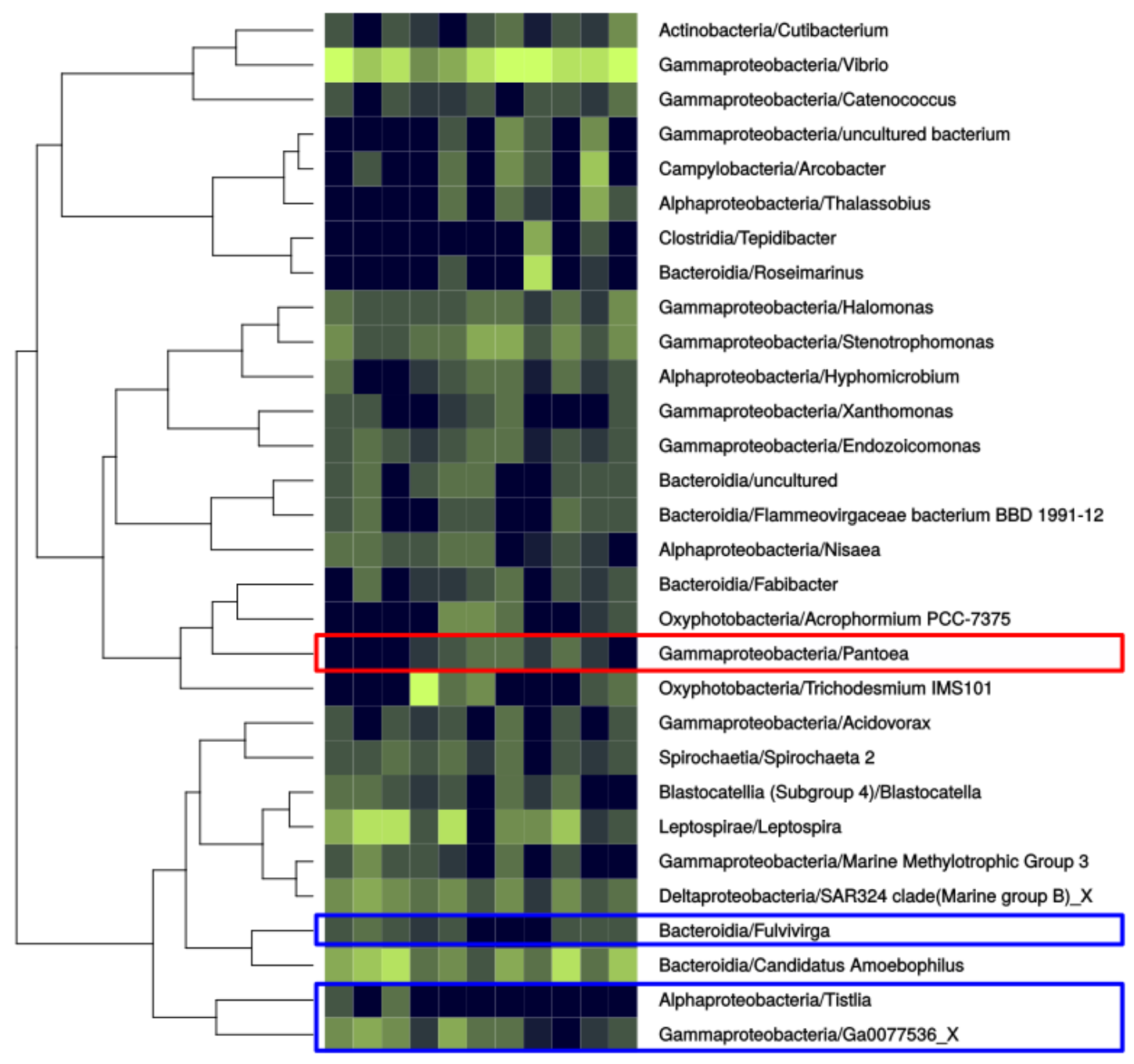

$3 \omega_{1} \omega_{1} 333, \omega_{1} \omega_{1} \omega_{1}$

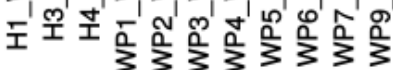

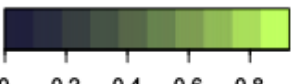




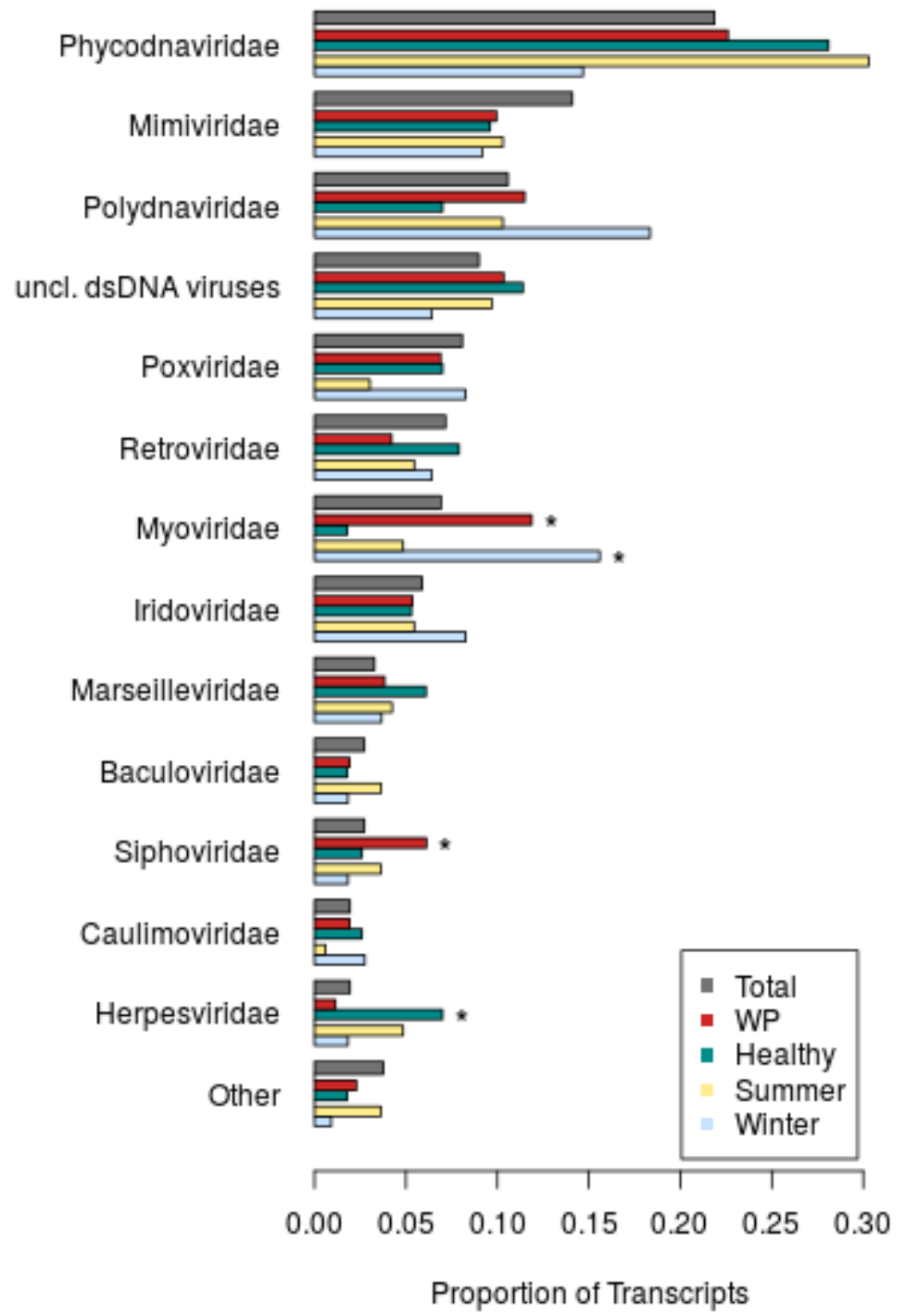




\section{Enriched GO terms - Biological Process}

Disease

\section{GO.ID \\ GO.Term}

GO:0009058

GO:0015031

GO:1901575

GO:0045927

GO:0007584

GO:0002183

GO:0006479

GO:0007568

GO:0016236

\section{Season}

\section{GO.ID}

GO:0010468

GO:0035556

GO:0006468

GO:0006357

GO:0042981

GO:0009887

GO:0008104

GO:0008285

GO:0007409

GO:0045930

GO:0009408

GO:0033209

GO:0048599 biosynthetic process

protein transport

organic substance catabolic process

positive regulation of growth

response to nutrient

cytoplasmic translational initiation

protein methylation

aging

macroautophagy

$\begin{array}{ccccc}\text { Total_transcripts } & \text { DE_transcripts } & \text { Up } & \text { Down } & \begin{array}{c}\text { P- } \\ \text { value }\end{array} \\ 10197 & 24 & 3 & 21 & 0.0286 \\ 3443 & 12 & 1 & 11 & 0.0264 \\ 4736 & 11 & 1 & 10 & 0.0857 \\ 468 & 5 & 0 & 5 & 0.0785 \\ 298 & 4 & 0 & 4 & 0.0429 \\ 132 & 3 & 1 & 2 & 0.0070 \\ 263 & 3 & 0 & 3 & 0.0378 \\ 428 & 3 & 0 & 3 & 0.0499 \\ 735 & 3 & 0 & 3 & 0.0730\end{array}$

P.

Total transcripts DE transcripts Up Down value

$\begin{array}{lllll}5992 & 29 & 25 & 4 & 0.072\end{array}$

$\begin{array}{lllll}4718 & 21 & 19 & 2 & 0.011\end{array}$

$\begin{array}{llll}16 & 14 & 2 & 0.032\end{array}$

$\begin{array}{lllll}2321 & 16 & 14 & 2 & 0.053\end{array}$

$\begin{array}{lllll}2069 & 13 & 13 & 0 & 0.002\end{array}$

$\begin{array}{lllll}2137 & 10 & 8 & 2 & 0.044\end{array}$

$\begin{array}{lllll}5183 & 9 & 8 & 1 & 0.005\end{array}$

$\begin{array}{lllll}752 & 9 & 8 & 1 & 0.006\end{array}$

$\begin{array}{lllll}1089 & 7 & 4 & 3 & 0.074\end{array}$

$\begin{array}{lllll}434 & 6 & 6 & 0 & 0.000\end{array}$

$\begin{array}{lllll}330 & 6 & 5 & 1 & 0.000\end{array}$

$\begin{array}{lllll}194 & 6 & 6 & 0 & 0.000\end{array}$

$\begin{array}{lllll}139 & 6 & 5 & 1 & 0.014\end{array}$ 